\title{
DEGRADATION OF THE SURFACE OF A METASILICATE GLASS DUE TO ATMOSPHERE MOISTURE
}

\author{
Ervino Carlos Ziemath
}

Departamento de Física - IGCE - UNESP - CP 178 - 13500-970 - Rio Claro - SP

Recebido em 2/12/96; aceito em 8/4/97

\begin{abstract}
Glasses with low silica content are very susceptible to suffer pronounced degradation when exposed to room atmosphere during short times. In this work the results of the degradation of the surface of a metasilicate glass with composition $2 \mathrm{Na}_{2} \mathrm{O} .1 \mathrm{CaO} .3 \mathrm{SiO}_{2}$ are presented. Optical and scanning electron microscopy observations, X-ray diffraction, infrared and Raman microprobe spectroscopic measurements of the modified surface of this glass show strong evidences that it is formed essentially by a crystalline carbonate layer.
\end{abstract}

Keywords: oxide glass; surface corrosion; vibrational spectroscopy.

\section{INTRODUCTION}

The physical chemistry features of glass surfaces are an important field in the glass science and glass industry. The internal surface of glass containers must be very stable with respect to the matter it contains like beverages, liquid or encapsulated medicaments, chemical reagents, etc., in order to maintain the integrity of the content. The surface of ophthalmic contact lenses and of optical fibres used in medical diagnosis (endoscopes) must be very stable and inert, or recovered with a suitable material in order to avoid troubles to patient's health, when in contact with living tissues or blood plasma. Windows and automobile glasses now produced present a good chemical stability, without visible modifications in their surfaces. The surfaces of modern glasses have a high chemical stability due to the choice of appropriate components for the melting and some special treatments during the final stages of the industrial production ${ }^{1,2}$.

Although all glasses have some degree of solubility in water solutions or undergo deterioration due to atmospheric and environmental conditions. One of the most troublesome example nowadays is related with the preservation of ancient glassware and medieval stained glass windows ${ }^{3-5}$.

Several glass and glass-ceramic compositions prepared for scientific research, with very interesting physical properties (optical, semiconducting, dielectric, mechanical, etc.), generally present unsuitable consequences when exposed to environmental atmospheric conditions. These inconveniences can be surpassed with the choice of appropriate coatings.

The combination of water vapor and carbon dioxide of the air can affect the entireness of oxide glasses surfaces in an irreversible manner. Freshly prepared surfaces of high silica content soda-lime glasses exposed to room atmosphere during some minutes show changes in the surface and sub-surface ( $600 \AA$ depth) composition ${ }^{6}$.

The process of glass weathering in damp atmospheres has long been known to result in the formation of sodium carbonate on the surface ${ }^{7,8}$. After Douglas and Isard ${ }^{8}$, at room temperature $\mathrm{Na}_{2} \mathrm{CO}_{3}$ will be formed on glasses exposed to $\mathrm{CO}_{2}$ in air saturated with water vapor, in which case the primary reaction is probably with an adsorbed layer of liquid water. For soda-lime silicate glasses they proposed the following sequence of reactions:

$$
\begin{aligned}
& \mathrm{H}_{2} \mathrm{O}_{(\mathrm{v})}+\mathrm{Na}_{2} \mathrm{O} \cdot(\mathrm{CaO})_{x} \cdot\left(\mathrm{SiO}_{2}\right)_{y} \rightarrow \mathrm{Na}_{2} \mathrm{O}+\mathrm{H}_{2} \mathrm{O} \cdot(\mathrm{CaO})_{x} \cdot\left(\mathrm{SiO}_{2}\right)_{y} \\
& \mathrm{Na}_{2} \mathrm{O}+\mathrm{H}_{2} \mathrm{O} \rightarrow 2 \mathrm{NaOH} \\
& \mathrm{Na}_{2} \mathrm{O}+\mathrm{CO}_{2} \rightarrow 2 \mathrm{~N} \mathrm{a}_{2} \mathrm{CO}_{3}
\end{aligned}
$$

Another proposition for the formation of carbonate salts on glass surfaces is presented by Rudd et $\mathrm{al}^{9}$ : the solubility of carbon dioxide in aqueous solution is much greater at high $\mathrm{pH}$ because the ionization of carbonic acid, $\mathrm{H}_{2} \mathrm{CO}_{3}$, and formation of carbonate salts. This occurs by the following reactions, where $\mathrm{Me}^{+}$is an alkali ion:

$$
\begin{aligned}
& \mathrm{CO}_{2}+\mathrm{Me}^{+}+\mathrm{OH}^{-} \leftrightarrow \mathrm{HCO}_{3}^{-}+\mathrm{Me}^{+} \\
& \mathrm{HCO}_{3}^{-}+2 \mathrm{Me}^{+}+\mathrm{OH}^{-} \leftrightarrow \mathrm{CO}_{3}^{2-}+2 \mathrm{Me}^{+}+\mathrm{H}_{2} \mathrm{O} \\
& 2 \mathrm{Me}^{+}+\mathrm{CO}_{3}^{2-} \leftrightarrow \mathrm{Me}_{2} \mathrm{CO}_{3}
\end{aligned}
$$

These reactions favor the dissolution and dissociation of carbon dioxide, when present, into carbonate in aqueous layer on the alkali silicate glasses.

In the present work it is shown that the surface of a sodalime metasilicate glass with composition $2 \mathrm{Na}_{2} \mathrm{O} .1 \mathrm{CaO} .3 \mathrm{SiO}_{2}$, exposed to room and high water vapor atmospheres, undergoes pronounced change in its chemical composition and structure, with the formation of carbonate and, in some cases, hydrated silicate layers. It is necessary to mention here that the results presented in this work are a consequence of incidental observations and sporadic measurements using several experimental techniques carried out along the last ten years.

\section{EXPERIMENTAL PROCEDURE}

\section{2.a) Sample Preparation}

Glass with composition $2 \mathrm{Na}_{2} \mathrm{O} \cdot 1 \mathrm{CaO} \cdot 3 \mathrm{SiO}_{2}$ was prepared using reagent grade sodium and calcium carbonates and quartz sand. The homogenized mixture was melted in platinum crucible in an electric furnace during about two hours at $1350^{\circ} \mathrm{C}$. Mechanical homogenization during melting was performed with a platinum-rhodium stirrer $(\sim 50 \mathrm{rpm})$. The melt was quenched between two steel plates, with a cooling rate fast enough to prevent crystallization. The final glass was colorless, transparent and without bubbles or striae. Glass pieces were initially store in simple plastic containers. Later, when the formation of a milky surface layer has been observed, they were stored in a desiccator with silica gel.

Two samples were submitted to X-ray diffraction measurements. The first one, with a plane surface, was stored during about 2 years in one of the plastic containers mentioned above and consequently presented a visibly milky and opaque surface. The other sample was exposed directly to room 
atmosphere during 2 months but in such a way that air dust was prevented to be deposited on the surface of interest, and the modified surface formed was thick enough in order that it could be easily removed with a sharp tool. Both samples were also submitted to infrared and Raman microprobe spectroscopic measurements.

Other samples were exposed to $100 \%$ rh (relative humidity) atmosphere during pre-established times according the following protocol. Hydrophilic cotton embedded with water was deposited on the bottom of equal glass containers. Sandpaper grounded and fractured samples were fixed on the inner side of the glass container crew cap with a double-side adhesive strips. After one day of exposure, visible water droplets were formed on the sample surfaces. The screw cap with the wetted sample surfaces were transferred to similar glass containers partially filled with silica gel in order to enable the slow evaporation of the droplets and the growth of crystals on them. Samples were exposed to saturated water vapor during 1, 2, 4 and 7 days. These samples were submitted to optical and scanning electron microscopy and Raman microprobe spectroscopy.

\section{2.b) Instrumentation}

Optical microscopic observations were performed with Neophot and Jenavert microscopes (Carl Zeiss/Jena). Scanning electron microscopic (SEM) studies were performed with a DSM 960 (Zeiss). X-ray diffraction patters were obtained with a Philips and a Rigaku Rotaflex diffractometers, using the $\mathrm{CuK} \alpha$ radiation $(\lambda=1.5418 \AA$ ), with a Ni filter. Infrared spectra were measured with a Nicolet 5SXC FT-IR Spectrometer. Powdered samples were supported by $\mathrm{KBr}$ pellets for transmittance measurements. The Diffuse Reflectance Unit 0030-001, of Spectra Tecn, Inc. (Barnes) was employed to measure reflection spectra of monolithic samples. Raman microprobe spectra were measured with a triple monocromator, XY Dilor Micro-Raman System, equipped with a Gold multichannel array detector, and the samples were excited with the $514.5 \mathrm{~nm}$ wavelength of an argon ion laser, Coherent Innova 70-2, with output power of about $700 \mathrm{~mW}$. The MicroRaman System was optically coupled to a BH-2 Olympus optical microscope, with a MS Plan 100X Dry objective (numerical aperture of 0.95 and work distance of $0.30 \mathrm{~mm}$ ).

\section{RESULTS AND DISCUSSION}

\section{3.a) Photomicrographs}

Figure 1 shows some optical and scanning electron photomicrographs of glass sample surfaces exposed to different atmospheric conditions.

Since the surface of the fractured glass sample (Fig. 1 (b)) was recovered with a crystallized layer it is possible that the crystal shown was accidentally deposited on it.

The photomicrographs presented in figure 1 reveal a high diversity of crystal morphologies that can be formed on the surface of a single glass sample exposed to different atmospheric conditions.

\section{3.b) X-Ray Diffraction}

The X-ray diffractograms of some samples exposed to different atmospheric conditions are presented in figure 2.

The main peaks in pattern (b) were identified to be of hydrated silicates: $\mathrm{Na}_{2} \mathrm{SiO}_{3} \cdot 6 \mathrm{H}_{2} \mathrm{O}$ (JCPDF 19-1238) and $\mathrm{Ca}_{1.5} \mathrm{SiO}_{3.5} \times \mathrm{xH}_{2} \mathrm{O}$ (JCPDF 33-0306) ${ }^{10}$. The non identified peaks in both patterns may be attributed to carbonates.

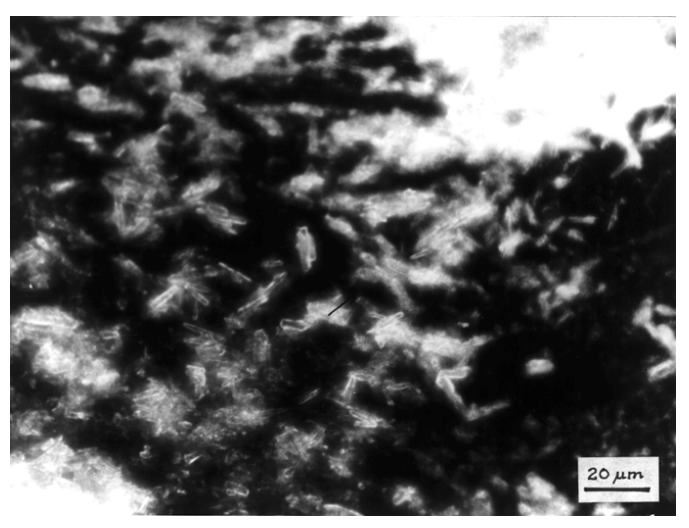

(A)

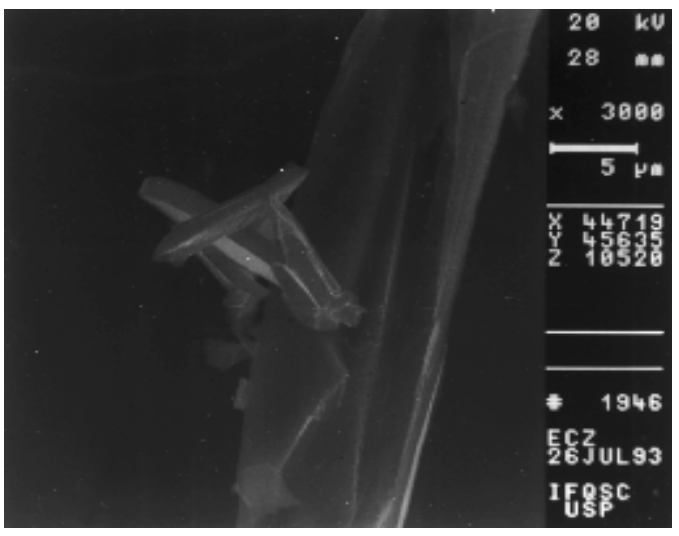

(B)

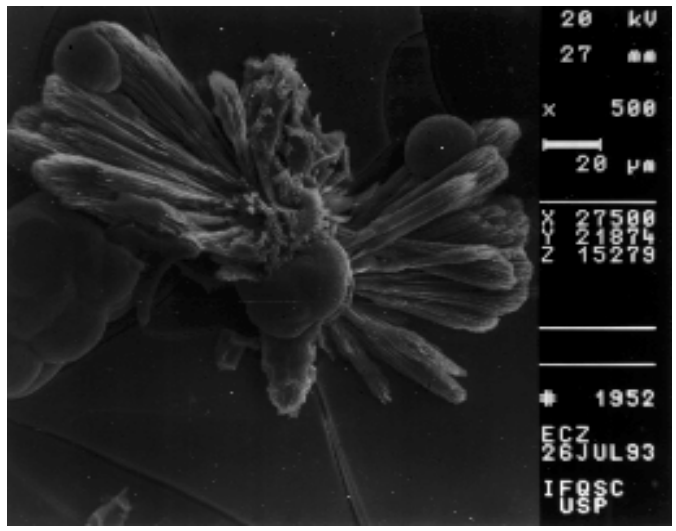

(C)

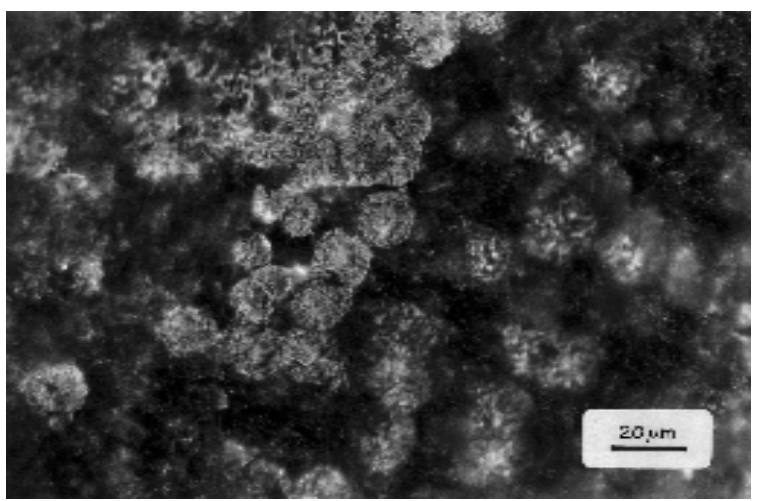

(C) 


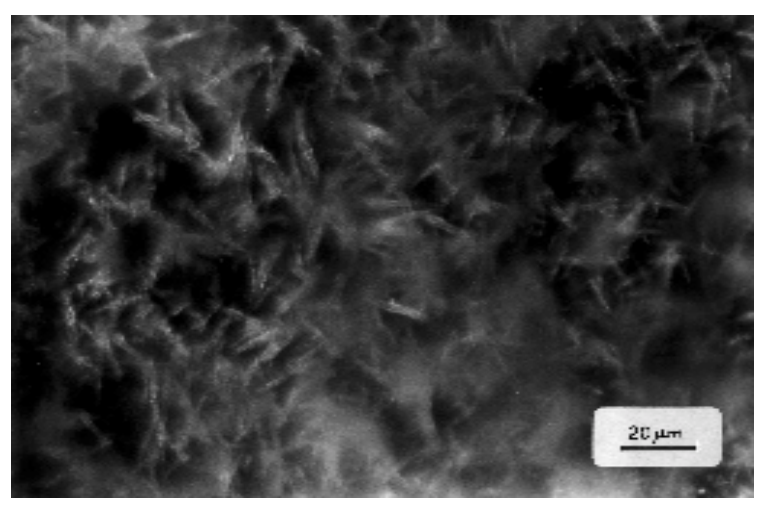

(E)

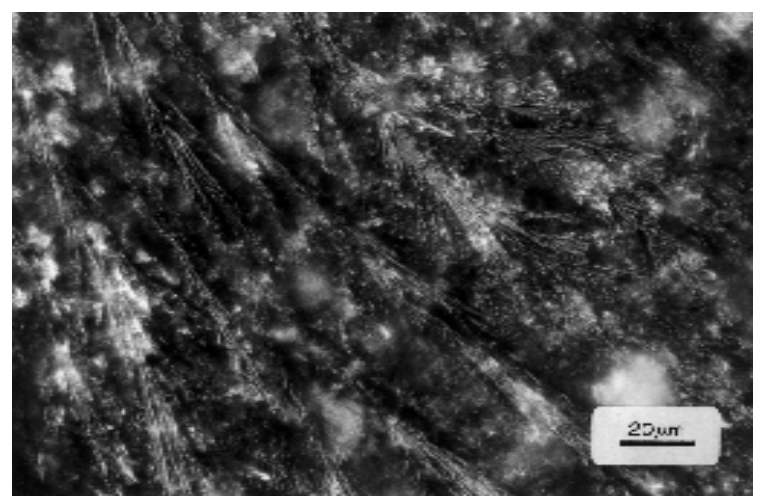

$(\boldsymbol{F})$

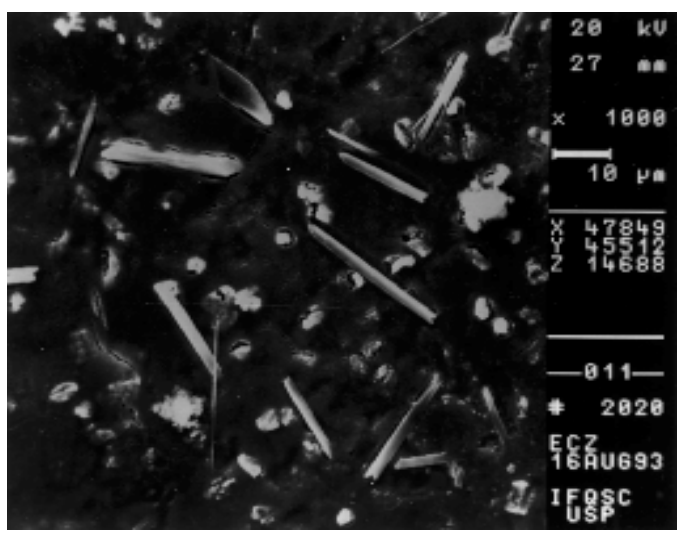

(G)

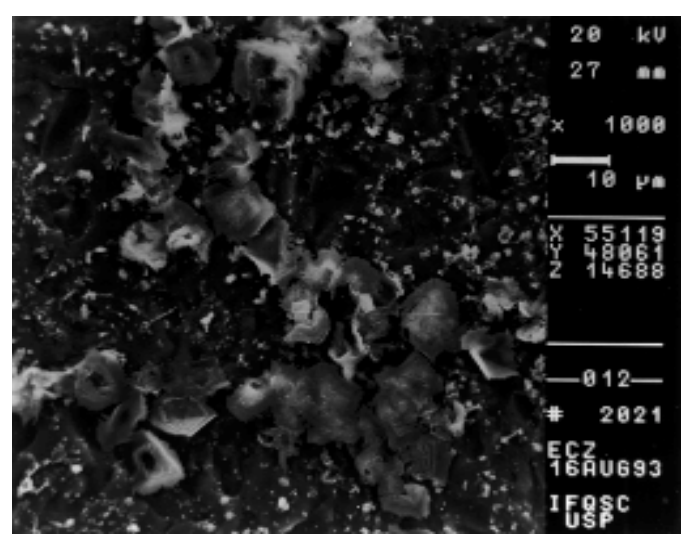

(H)

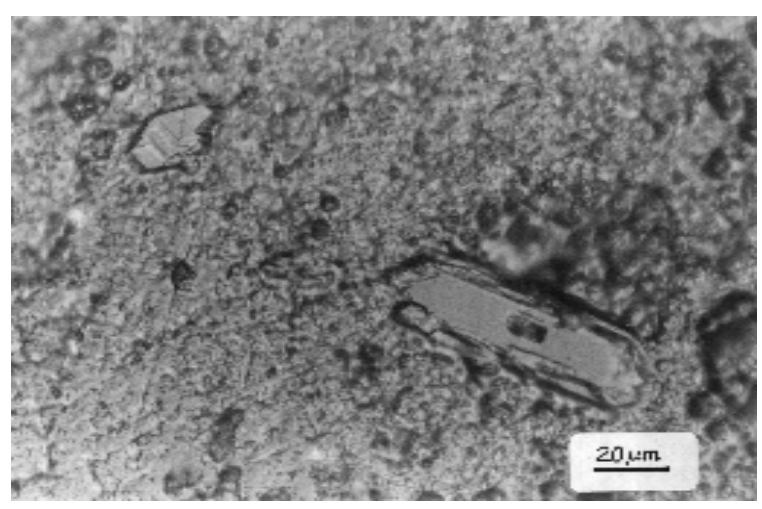

(I)

Figure 1. Photomicrographs of the surfaces of glass samples exposed to different atmospheric conditions: (a) sample stored in a simple plastic container during about 3 years (Neophot microscope, reflection, dark field; the first one); (b) crystal deposited on a fractured surface, stored in a desiccator (SEM); (c) sample exposed to 100\% rh water vapor during 7 days (SEM); (d) same as in (c), but observed with optical microscope (Jenavert, reflection); (e) same as in (d), on other area of the sample; $(f)$ same as in $(d)$, on other area of the sample; $(g)$ exposed to $100 \%$ rh water vapor during 4 days (SEM); (h) same as in $(\mathrm{g})$, on other area; $(i)$ exposed to $100 \%$ rh water vapor during 2 days (Jenavert, reflection).
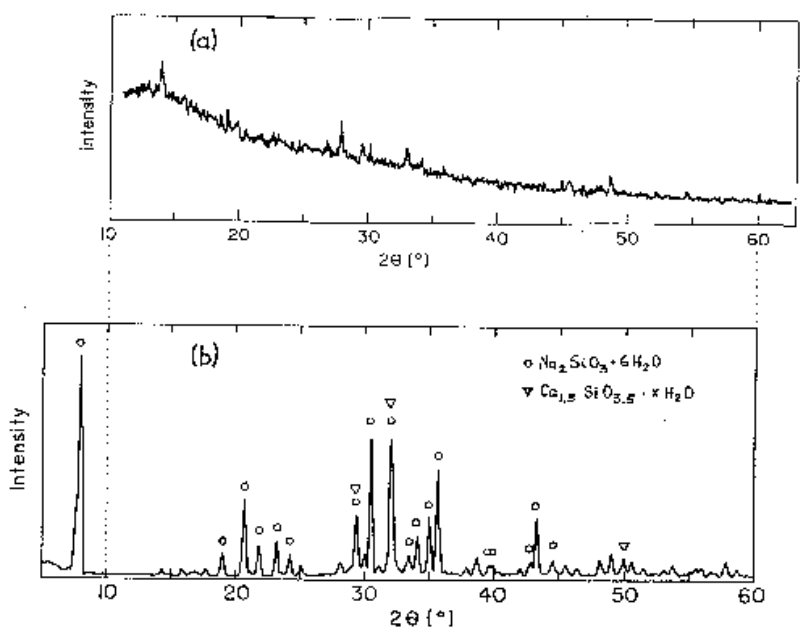

Figure 2. X-ray diffraction patterns of crystals formed on glass surfaces exposed to different atmospheric conditions: (a) monolithic sample stored in a common plastic container during about 2 years; (b) powdered crystalline material removed from the surface of a sample exposed to room atmosphere during 2 months.

\section{3.c) Infrared Spectroscopy}

Transmission and reflection infrared spectra are presented in figure 3. Spectrum (a) was obtained from the same crystalline powder as that which gives the X-ray diffraction pattern (b), shown in figure 2. The powder was supported by a $\mathrm{KBr}$ pellet. This spectrum is very similar to that of carbonate substances ${ }^{11-15}$. The diffuse reflection spectrum (b) was measured for crystals formed on the surface of a glass sample exposed to room atmosphere during about 2 months. The spectra shown in the insets are those of the glass matrix ${ }^{16}$ which present no resemblance with those of the crystallized surface layer.

It should be mentioned that infrared radiation has a penetration depth of about $0.5 \mu \mathrm{m}$ in silicate glasses ${ }^{17,18}$. The penetration depth of this radiation in carbonates has not been found in the literature by the author. But supposing that the 
crystallized layer on the glass surface is mainly formed by a sodium and/or calcium carbonate, and that the layer has a thickness higher than $5 \mu \mathrm{m}$, which is the width of the larger crystal shown in figure 1 (b), the penetration depth of the infrared radiation should be less than $5 \mu \mathrm{m}$. This is in agreement with the reflection infrared spectrum presented in figure 3 (b), where bands due to the precursor glass substrate or any other silicate compound are not observed.

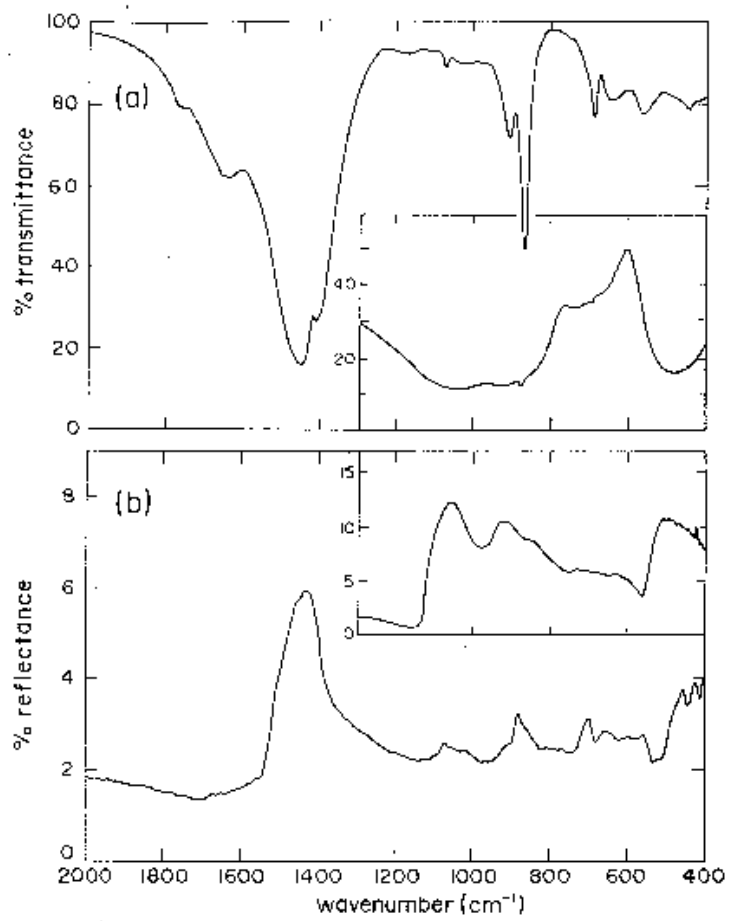

Figure 3. FTIR spectra of samples exposed to room atmosphere during 2 months: (a) transmittance spectrum of the crystalline powder removed from the glass surface; (b) diffuse reflection spectrum of the crystallized layer formed on the glass surface. Insets: spectra of the unmodified (original) glass.

\section{3.d) Raman Microprobe Spectroscopy}

Non-polarized Raman microprobe spectra of several samples are presented in figure 4 . The spectra were not corrected to frequency nor to temperature (these corrections are generally made when the low frequency region of the spectra are studied $^{19}$, which is not the scope in the present work.)

Spectrum (a) was obtained from the glass surface after removing the crystallized layer. This spectrum is essentially the same as that of the bulk one ${ }^{16}$.

Spectrum (b) was obtained from a single crystal formed on the surface of the sample exposed to room atmosphere during 2 months. The wide and low intensity bands at frequencies higher than $550 \mathrm{~cm}^{-1}$ are due to the glass matrix, while the narrow and strong peak at $1071 \mathrm{~cm}^{-1}$ is characteristic of a crystalline material. This spectrum reveals the superposition of two different spectra: from the glass substrate and from the crystallized layer. This superposition is explained in terms of the focal cylinder depth, of about $4 \mu \mathrm{m}$, of the laser beam that incides on the sample, which excites simultaneously the glass substrate and the crystallized layer. Such observations lead to conclude that the crystallized layer in the region where the laser beam was focused has a thickness less than $4 \mu \mathrm{m}$.

The same strong peak at $1071 \mathrm{~cm}^{-1}$ is also present in spectrum (c), taken from the removed crystallized layer formed on a glass sample exposed to room atmosphere during 2 months.

The crystalline layer of a glass exposed to saturated water

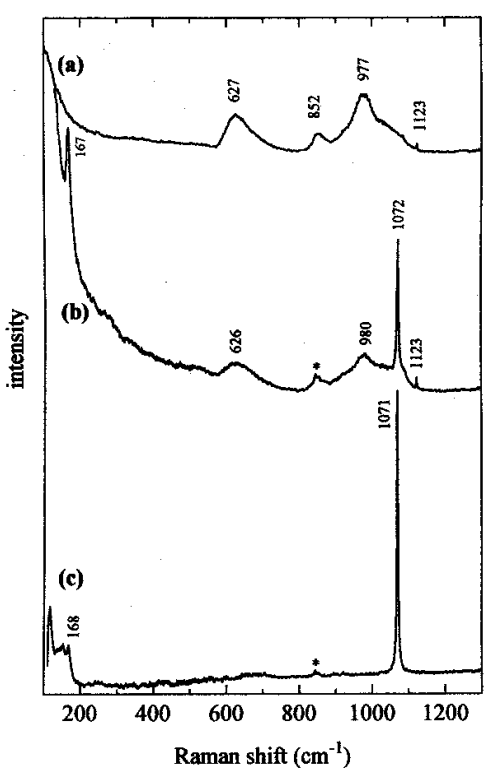

$(A, B, C)$

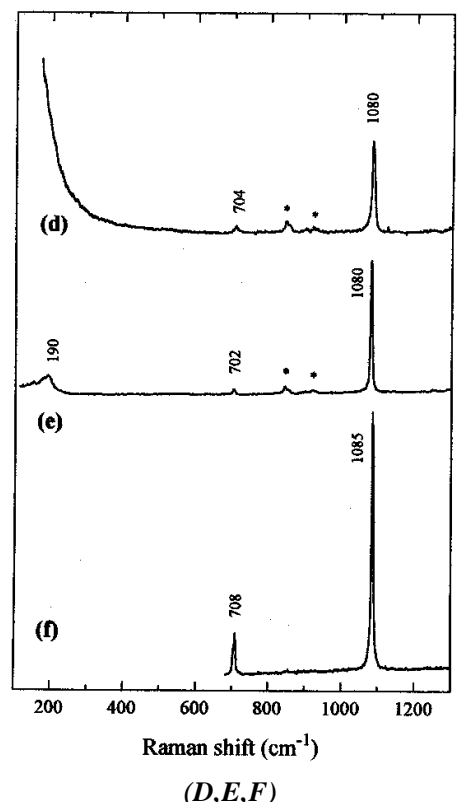

Figure 4. Raman microprobe spectra: (a) $2 \mathrm{Na}_{2} \mathrm{O} .1 \mathrm{CaO} .3 \mathrm{SiO}_{2}$ glass; (b) a crystal formed on the glass surface exposed to room atmosphere during 2 months; (c) a crystal removed from the crystallized layer of a glass surface exposed to room atmosphere during 2 months; (d) agglomerate of crystals grown on the glass surface exposed to water vapor (100\% rh) during 7 days; (e) reagent grade $\mathrm{Na}_{2} \mathrm{CO}_{3}$; (f) "dead" pearl. (The bands marked with asterisk are due to the resonant Raman effect of the anti-reflecting coating of the microscope objective.)

moisture during 7 days presents the spectrum shown in (d), where a narrow and strong peak appears at $1081 \mathrm{~cm}^{-1}$, and another broader one and less intense at $704 \mathrm{~cm}^{-1}$.

The spectra (e) and (f) were obtained from reagent grade sodium carbonate $\left(\mathrm{Na}_{2} \mathrm{CO}_{3}\right.$, Aldrich) and from a "dead" pearl, respectively. The pearl spectrum is nearly the same as that of calcite, $\mathrm{CaCO}_{3}{ }^{15,20}$, except by the splitting of the two bands at 705 and $1086 \mathrm{~cm}^{-1}$, which could be an effect due to the small birefringence of microcrystals of the calcium carbonate (aragonite structure ${ }^{21}$ ) or due to the multilayer morphology of the pearl. 
The spectrum (e), of sodium carbonate, presents bands at 702 and $1079 \mathrm{~cm}^{-1}$, both displaced to lower frequencies with respect to those of the calcite spectrum ${ }^{15,20}$. The spectra of carbonates are essentially due to the vibrational modes of $\mathrm{CO}_{3}{ }^{2}$, but the cationic ions $\left(\mathrm{Me}^{+}\right.$or $\left.\mathrm{Me}^{2+}\right)$ induce different local fields around the carbonate ions, an these produces the frequency shift of the bands. These leads to conclude that the sharp bands in the spectra (b) to (d) are due to the symmetric stretching vibration of the carbonate ions, and that the main crystals formed on the glass surface are carbonates.

\section{CONCLUSIONS}

According to the results presented in this work, it can be concluded that the surface layer formed on the $2 \mathrm{Na}_{2} \mathrm{O} .1 \mathrm{CaO} .3 \mathrm{SiO}_{2}$ glass exposed to room moisture is essentially composed by carbonate crystals.

Sources of carbon to form the carbonates can be found in the bulk glass as well as in the surrounding atmosphere.

It is long be known that the gases evolved from glasses heated in vacuum consist largely of $\mathrm{H}_{2} \mathrm{O}$ vapor, small quantities of $\mathrm{CO}_{2}$ and traces of other gases ${ }^{22,23}$. The more recent literature presents Auger, secondary ion mass and X-ray photoelectron spectroscopic measurements with well defined peaks due to $\mathrm{C}, \mathrm{CO}^{+}$and $\mathrm{CO}_{2}{ }^{+17,24-27}$. These ionic carbon compounds in the bulk glass are formed during the melting process: the decomposition of the carbonates added to the batch liberates $\mathrm{CO}_{2}$ to the atmosphere or reacts with oxygen ions $\left(\mathrm{O}^{2-}\right)$ in the melt to form carbonate ions $\left(\mathrm{CO}_{3}{ }^{2-}\right)^{23}$, which are retained in the glass.

In the preparation of the $2 \mathrm{Na}_{2} \mathrm{O} .1 \mathrm{CaO} .3 \mathrm{SiO}_{2}$ glass an appreciate quantity of sodium and calcium carbonate were used, but Raman and infrared spectra of the bulk glass ${ }^{16}$ show no evidence of bands which can be attributed to vibrations of carbonate ions. There are two main explanations to this fact: no $\mathrm{CO}_{3}{ }^{2-}$ ions are present or its concentration is too low to be detected by these spectroscopic techniques.

The other source of carbon is the room atmosphere, where the concentration of $\mathrm{CO}_{2}$ is about $0.02-0.05$ vol\% ${ }^{28}$. Human breath exhales about 3 vol\% of this gas ${ }^{28}$, and air pollution has increased its concentration in the last years. But according to the reactions presented in the introduction of this work, the carbon dioxide gas can only cause degradation of the glass surface if there exist at least a thin layer of an alkaline solution. The studied glass is considerably hygroscopic, and the water adsorbed on its surface removes a large quantity of $\mathrm{Na}^{+}$and $\mathrm{Ca}^{2+}$ ions from its surface and sub-surface layers. Thus, there is an alkaline solution to promote the reaction sequence mentioned early. The fluctuations of the room temperature and relative humidity promote a fluctuation in the adsorption and desorption of water. With the evaporation of water, carbonate crystals are formed on the glass surface, which are easily detected by infrared and Raman spectroscopy.

The main contradiction in the results is the determination of the hydrated silicates by X-ray diffraction, since they were not detected by infrared and Raman spectroscopy. The alkaline solution formed on the glass surface attacks the remaining glass more readily and dissolves the silica network which, in this glass, is formed essentially by $\left(\mathrm{Si}_{2} \mathrm{O}_{6}{ }^{4-}\right)_{n}$ chains. ${ }^{16}$ The deterioration can thus be very pronounced and, depending on the atmospheric conditions, small fragments of the degraded glass can be produced. According to the X-ray diffractogram presented in figure 2 (b), these fragments are constituted essentially by crystalline hydrated silicates and a very small volume fraction of carbonates.

\section{ACKNOWLEDGEMENTS}

The author wish to express kindly thanks to Mr. Carlos Trombella, Mr. José Augusto L. da Rocha and Mr. Geraldo
Catarino for the X-ray diffraction measurements; to Prof. Dr. Ana M. Plepis for the infrared spectroscopy measurements; to Prof. Dr. Maria S. S. Dantas and Prof. Dr. Marcos A. Pimenta for the assistance with the Raman microprobe measurements; and to Prof. Dr. Michel A. Aegerter for the permission to use the SEM facilities in the IFSC-USP, São Carlos (Brazil). Also, financial supports of Brazilian institutions: FAPESP (Grant Nos. 85/2619-6, 88/2931-8, and 93/4959-5) and FUNDUNESP (Grant No. 506/94-DFP/F/CET) are greatly appreciated.

\section{REFERENCES}

1. Scholes, S. R.; Greene, C. C.; Modern Glass Practice; Cahners Pub. Co.; Boston, 1975; pp. 62-92, 413-415.

2. Rawson, H.; Glasses and their Applications; Institute of Metals; London, 1991; pp. 28, 31-33.

3. Hench, L. L.; Newton, R. G.; Bernstein, S.; Glass Technol. 1979, $20,144$.

4. Müller, W. Bol. Soc. Esp. Ceram. Vid. 1992, 31-C, 219.

5. Müller, W.; Torge, M.; Adam, K.; Glastech. Ber. Glass Sci. Technol. 1994, 67, 45.

6. Hench, L. L.; Clark, D. E.; J. Non-Cryst. Solids 1978, $28,83$.

7. Douglas, R. W.; Isard, J. O.; J. Soc. Glass Technol. 1949, 33, T288.

8. Tichane, R. M.; Glass Technol. 1966, 7, 26.

9. Rudd, G. I.; Garofalini, S. G.; Hensley, D. A.; J. Am. Ceram. Soc. 1993, 76, 2555.

10. Powder Diffraction File - Inorganic Volume; Berry, L. G.; Ed. JCPDF; Philadelphia, PA; 1983.

11. Niquyst, R. A.; Kagel, R. O. Infrared Spectra of Inorganic Compounds; Academic Press; New York, 1971; pp. 76-79.

12. The Aldrich Library of FT-IR Spectra; Pouchet, C. J., Ed.; Aldrich Chemical Company; Milwaukee, Wisc., 1989; pp. 545 A (Vol. 1), 1272 C (Vol. 2).

13. Adler, H. H.; Kerr, F. P.; Am. Mineral. 1963, 48, 124.

14. Adler, H. H.; Kerr, F. P.; Am. Mineral. 1963, 48, 839.

15. Scheetz, B. E.; White, W. B.; Am. Mineral. 1977, 62, 36.

16. Ziemath, E. C.; Aegerter, M. A.; J. Mater. Res. 1994, 9, 216.

17. Hench, L. L.; Clark, D. E.; J. Non-Cryst. Solids 1978, 28,83 .

18. Geotti-Bianchini, F.; de Riu, L.; Gagliardi, G.; Guglielmi, M.; Pantano, C. G.; Glastech. Ber. 1991, 64, 205.

19. Galeener, F. L.; Leadbetter, A. J.; Stringfellow, M. W.; Phys. Rev. B 1983, 27, 1052.

20. Long, D. A.; Raman Spectroscopy; McGraw-Hill; London, 1977; p. 204.

21. Schumann, W.; Gemas do Mundo, 3rd ed. (translated from Edelsteine und Schmucksteine; BLV Verlagsgesellschaft; München, 1976); Ao Livro Técnico S/A.; Rio de Janeiro, 1985; p. 222.

22. Holland, L.; The Properties of Glass Surfaces; John Wiley; New York, 1964; pp. 210-218.

23. Scholze, H.; Glass Ind. 1966, 47, 546. Ibid. 1966, 47, 622.

24. Pantano Jr., C. G.; Dove, D. B.; Onoda Jr., G. Y.; J. NonCrystal. Solids 1975, 19, 41.

25. Chappell, R. A.; Stoddart, C. T. H.; J. Mater. Sci. 1977, 12,2001

26. Fox, P. G.; Glass Technol. 1981, 22, 67.

27. Dunken, H. H.; In: Physikalische Chemie der Glasoberfläche; Dunken, H. H.; Ed.; VEB Deutscher Verlag für Grundstoffindustrie; Leipzig, GDR, 1981; p. 145, 157.

28. Guenther, W. B.; Química Quantitativa: Medições e Equilíbrio (translated from Quantitative Chemistry: Measurements and Equilibrium; Addison-Wesley; Reading, Mass., 1968); Editora Edgard Blücher/EDUSP; São Paulo, 1972 ; p. 318. 